\title{
JUSTIÇA E SEGURANÇA PÚBLICA DESDE UMA PERSPECTIVA DE TRANSIÇÃO
}

\author{
JUSTICE AND PUBLIC SECURITY FROM A TRANSITIONAL PERSPECTIVE
}

Antonio Sérgio Escrivão Filho ${ }^{1}$ Fernando Luis Coelho Antunes ${ }^{2}$

Resumo: $O$ Brasil passou por um processo tardio de reconstrução da sua história no que diz respeito à Justiça de transição. Entre os elementos que desde uma perspectiva conceitual compõem uma noção de Justiça de transição encontram-se os processos compreendidos pelas reformas institucionais, caracterizados pela realização de medidas voltadas à reeducação e refuncionalização das instituições públicas, a fim de reorientá-las para o cotidiano do Estado Democrático de Direito, com vistas à promoção dos direitos humanos, extirpando resquícios autoritários das estruturas normativas, institucionais e culturais do Estado. No interior desse debate, as instituições de justiça e segurança pública são comumente identificadas como alvos prioritários de processos de transição, dada a sua relação intrínseca e direta com o tratamento da violência política sistemática e a restrição de direitos e liberdades. Nesse sentido, o artigo apresenta uma discussão sobre o cenário das reformas institucionais referentes ao poder judiciário e aos sistemas de segurança pública, em um esforço analítico para contribuir com os debates realizados no contexto tardio de Justiça de transição no Brasil.

Palavras-chave: Justiça de transição. Reformas institucionais. Poder Judiciário. Segurança pública. Brasil.
Abstract: Brazil has passed through a delayed reconstruction process of its history, from a perspective of the so called transitional justice. Among the elements that usually make up a conceptual notion of transitional justice, it can be found the processes understood by institutional reforms, characterized by carrying out measures aimed at reeducation and refunctionalization of public institutions, in order to redirect them to the Democratic Rule of Law, and the promotion of human rights, putting away authoritarian remnants from normative, institutional and cultural public structures. Within this debate, the institutions of justice and public security are commonly identified as priority targets for transition processes, because of its intrinsic and directly relation to the treatment of systematic political violence and the restriction of rights and freedoms. In this sense, the article presents a discussion on the scenario of institutional reforms regarding the judiciary, public security in the context of the late Transitional Justice in Brazil.

Keywords: Transitional justice. Institutional reforms. Judicial role. Public security. Brazil.

\footnotetext{
1 Doutor em Direito, Estado e Constituição pela Universidade de Brasília; Graduado e Mestre em Direito pela Universidade Estadual Paulista; Professor no Instituto de Ensino Superior de Brasília; antonio@terradedireitos.org.brorg.br

2 Doutor em Direito, Estado e Constituição pela Universidade de Brasília; Professor na Universidade Católica de Brasília; EPCT OS 7 LT 1, Águas Claras, 71966-700, Brasília, Distrito Federal, Brasil; fernandoantunes07@gmail.com
} 


\section{Introdução}

Em que pesem o advento da nova ordem constitucional e a retomada do regime democrático no Brasil com o fim da ditadura militar, pode-se afirmar, como se desenvolve ao longo deste estudo, que a transição do período de exceção para o momento democrático ocorreu de forma controlada e, portanto, incompleta, permanecendo na estrutura, organização e cultura das instituições estatais elementos conservadores da ordem autoritária, a exemplo, para fins da presente análise, do poder judiciário e do sistema de segurança pública.

Observam-se, nesse sentido, resquícios autoritários no âmbito de tais sistemas institucionais que respondem a um ambiente político, econômico, social e cultural de violações de direitos humanos, fomentando ainda hoje, tardiamente, uma cultura institucional ora alheia ora avessa à garantia, promoção e defesa dos direitos humanos no Brasil; algo que ocorre, notadamente, nas agências relacionadas ao controle penal, como as polícias, as Forças Armadas, as secretarias de segurança e o sistema penitenciário, que compõem os órgãos do sistema de segurança pública, responsáveis pelo controle da ordem pública.

Essa transição incompleta significa o convívio cotidiano com práticas autoritárias e excludentes que atingem direitos e garantias fundamentais, assim como o desrespeito a regras e princípios presentes em documentos internacionais de proteção aos direitos humanos, entre as quais podem ser citadas a criminalização de movimentos sociais e a baixa densidade política e consequentemente normativa dos direitos econômicos, sociais e culturais, sobretudo em face do sistema de justiça.

Nesse mesmo sentido da manutenção de práticas institucionais que violam direitos, observa-se que são recorrentes as denúncias de torturas em penitenciárias e departamentos policiais, bem como relatórios $^{3}$ de execuções sumárias e extrajudiciais promovidas por agentes do Estado, a maioria das quais são definidas como "resistência seguida de morte", o que se soma à ineficiência no controle externo sobre as polícias, o excesso de letalidade e uso de força em ações estatais de desocupação e intervenção em conflitos sociais, e o elevado número de presos provisórios no Brasil, entre outras violações sistemáticas de direitos humanos. Permanece, portanto, na estrutura estatal nacional, a ausência de uma limitação eficiente do arbítrio dos agentes estatais em muitos casos, notadamente em expressões legítimas da democracia, como reivindicação de direitos, protestos, greves e demais manifestações.

Considerando esse diagnóstico, parece necessário reconhecer a extensão do papel e das ações de agentes estatais, órgãos públicos, empresários, proprietários rurais e entidades da sociedade civil que colaboraram com o regime autoritário, com o intuito de reformar, eventualmente suprimir,

\footnotetext{
3 Os relatórios e bancos de dados sobre violações de direitos produzidos por organizações da sociedade civil são fontes importantes de pesquisa e demonstram a extensão do problema no Brasil. Destaca-se, por exemplo, o Banco de Dados produzidos pelo Núcleo de Estudos da Violência da Universidade de São Paulo (NEV - USP), o qual possui diversos textos, artigos, estatísticas e casos relacionados à violência policial, notadamente a pesquisa: Casos envolvendo policiais da Rota - 1980 a 2011 , bem como o $5^{\circ}$ Relatório sobre os Direitos Humanos no Brasil (2001-2010).
} 
e adequar as instituições públicas aos preceitos de um Estado Democrático de Direito. É certo, outrossim, que no Brasil o sistema de segurança pública e o sistema de justiça desempenharam papéis centrais ora em medidas repressivas voltadas a cercear direitos, ora em uma cumplicidade silenciosa, omissiva e leniente diante da prática de graves violações de direitos humanos por agentes estatais.

Aliados a esse cenário institucional, a relação e colaboração mútua entre esferas do poder judiciário, setores do aparato da segurança pública e os militares do poder executivo proporcionou a elaboração de uma espécie peculiar de "legalidade autoritária" (PEREIRA, 2010, p. 36), ${ }^{4}$ preocupada e orientada a revestir de validade jurídica as práticas autoritárias da ditadura civil-militar. Há que ressaltar, no entanto, que explorar a relação entre o poder judiciário e o sistema de segurança pública no período de exceção é interessante, porém limitado, pois o autoritarismo exercido sobre a estrutura jurídica pelos atos institucionais visava, justamente, criar um mecanismo de sustentação jurídica das graves violações de direitos humanos, na medida em que estas não poderiam ser objeto da atuação, e, portanto, reconhecidas oficialmente pelos órgãos jurisdicionais, dada a exclusão dos atos de governo da esfera de apreciação judicial (Ato Institucional n. 5, art. 11), o que seria agravado pela suspensão do habeas corpus para crimes políticos, contra a segurança nacional, a ordem econômica e a economia popular (AI-5, art. 10). ${ }^{5}$

Compreende-se, assim, que a constatação dessa herança autoritária em instituições como o poder judiciário e o sistema de segurança pública demanda uma agenda de reformas institucionais para seus órgãos, sendo indispensável compreendê-las no contexto de transição.

Nesse sentido, por meio de uma pesquisa eminentemente bibliográfica, sustentada por análises normativas e documentais, o presente artigo apresenta um estudo orientado pelas categorias analíticas da Justiça de transição, em especial a noção de reformas institucionais aplicadas ao cenário institucional do poder judiciário e do sistema de segurança pública de modo a suscitar uma avaliação sobre os limites dos processos de reformas institucionais orientadas para a sua refuncionalização e adequação ao regime democrático e as consequências desse cenário no que diz respeito à promoção ou reiteração da violação dos direitos humanos na atualidade.

\section{Reformas institucionais no contexto de transição}

A fim de delimitar o tema em análise, emprestamos o conceito de Teitel (2003, p. 69) para compreender a justiça de transição "como a concepção de justiça associada a períodos de mudança

\footnotetext{
4 Para um exame substancioso desse conceito consultar Anthony Pereira, que também utiliza a expressão "judicialização da repressão" para designar a elaborada regulamentação normativa que os prisioneiros políticos recebiam (PEREIRA, 2010).

5 Analisando a atuação do Supremo Tribunal Militar no período da ditadura, Domingues da Silva afirma que: "Por mais interessante que seja, trazendo à tona a rotina e alguns temas debatidos no STM, a documentação pesquisada no Arquivo do STM - Atas das Sessões, Ofícios Recebidos e Expedidos pela Presidência - possui alguns limites. Temas como tortura e desaparecimento permaneceram à sombra em meio à profusão de assuntos debatidos no plenário do Tribunal. Não faltam referências documentais e bibliográficas comprovando a utilização de tal prática desde os primeiros dias de abril de 1964, contudo, este tema permaneceu praticamente velado na documentação do STM disponível para consulta, até 1975." (DOMINGUES DA SILVA, 2011, p. 107).
} 
política, caracterizada por respostas legais para enfrentar as ilegalidades de regimes repressivos antecessores."

Neste ambiente conceitual, a necessidade de realização de reformas institucionais apresenta-se como um dos elementos, estratégias ou processos componentes da justiça de transição, guardando relação de interdependência com os componentes de justiça, busca pela verdade, reparação e reconciliação. De fato, Abrão e Torelly (2011, p. 215) anotam que a justiça de transição é composta por ao menos quatro dimensões fundamentais identificadas pelas dimensões de: reparação; fornecimento da verdade e construção da memória; regularização da justiça e restabelecimento da igualdade perante a lei; e reforma das instituições perpetradoras de violações contra direitos humanos. Nesses termos, observa-se no âmbito deste campo analítico voltado ao estudo da justiça de transição, um consenso ${ }^{6}$ em admitir a inserção das reformas institucionais como um padrão recorrente nos processos transicionais ocorridos ao longo do século XX, sem olvidar, no entanto, que a justiça de transição se manifesta de modo essencialmente histórico e contextual, o que lhe confere características sempre muito próprias em relação a um pretenso padrão ou tipo ideal que se lhe procure atribuir (QUINALHA, 2013, p. 165).

Segundo Quinalha (2013, p. 149), as reformas institucionais permeiam todos os demais eixos componentes da justiça transicional, ao passo em que estão diretamente relacionadas à instauração do Estado Democrático de Direito e ao fortalecimento das suas instituições a partir do paradigma político da democracia, tendo por finalidade a garantia de não repetição das violações de direitos humanos.

Para Brito (2009, p. 82), as reformas institucionais apresentam um elemento específico em relação aos demais componentes transicionais, haja vista que operam a reintegração política das instituições públicas para a democratização do Estado e da sociedade. De fato, as reformas institucionais estão diretamente referidas às medidas direcionadas às transformações das instituições públicas e, por esse motivo, situam-se na esfera eminentemente política da justiça de transição, enquanto as medidas de memória e justiça apontam, por exemplo, para um sentido de reintegração social.

Importa, nesse sentido, identificar a especificidade dessas dimensões, a fim de reconhecer a intrínseca relação de interdependência e complementaridade entre os diferentes componentes da justiça de transição. ${ }^{7}$ Quinalha (2013, p. 160) aponta, por exemplo, uma crítica aos mecanismos transicionais oficiais e às abordagens tradicionais que ignoram ou marginalizam os abusos de ordem social, econômica e cultural realizados pelos períodos de repressão, ao passo que Brito (2009, p. 83) identifica justamente nas reformas institucionais um caráter de "reintegração política, que normal-

\footnotetext{
6 Cf, por todos, Teitel (2003) e Van Zyl (2009).

7 Vale ressaltar, inclusive, que, na medida da sua realização e variações históricas, observa-se a predominância de certos eixos em relação a outros, o que responde a conjunturas e estratégicas específicas de alcance da paz e/ou da justiça em cada processo transicional. Abrão e Torelly (2012, p. 71) afirmam, por exemplo, que no Brasil os componentes da reparação, memória e verdade vêm representando os eixos de maior desenvolvimento no processo tardio de justiça transicional, ao passo que as reformas institucionais ainda se revelam quase nulas no que se refere às Forças Armadas, Sistema de Segurança e Justiça Militar.
} 
mente exige uma resposta para categorias mais amplas de exclusão econômica e social e, em alguns casos, étnica."

No Brasil, uma investigação sobre os contornos da atuação do regime militar sobre a questão agrária parece refletir de modo bastante evidente a forma como o regime autoritário contribuiu para o agravamento da exclusão econômica e social de camponeses, tribos indígenas e comunidades tradicionais. Como observa Sauer (2010), a chamada "modernização conservadora" imprimida ao campo brasileiro nos termos da política de desenvolvimento do regime autoritário, carregava consigo uma genética ambivalente que agregava tecnologia produtiva e violação de direitos humanos dos povos, comunidades e trabalhadores que vivem no campo e nas florestas:

O apoio à modernização do latifúndio deu ao programa seu caráter conservador. [...] O cultivo de grandes extensões - padrão predominante do modelo de modernização - aumentou a produção agrícola do país. Não promoveu, porém, o bem-estar social da maioria da população rural, ao contrário, provocou concentração da propriedade da terra, êxodo rural, fome e violência. (SAUER, 2010, p. 30).

Como aponta Martins (1980, p. 53), a aposta de que a modernização tecnológica configuraria a solução para os problemas agrários viria revelar-se no seu próprio elemento de intensificação, resultando no agravamento da exclusão social e concentração fundiária.

Não é em outro sentido, por exemplo, que o primeiro balanço de atividades da Comissão Nacional da Verdade (CNV), da Presidência da República apontou que o denominado "Relatório Figueiredo", documento mantido sob sigilo militar até o advento da CNV (BRASIL, 2013, p. 6) - que o revelava "informações sobre várias formas de violação de direitos como maus tratos e assassinatos de índios, perda de terras indígenas para fazendeiros e empresários, desvio de verbas, negociatas e negligência com população em extinção."

Já o relatório final da CNV, por seu turno, ressalta o impacto já inaugural do autoritarismo militar sobre as organizações camponesas, notadamente com a cassação do mandato de deputado federal de Francisco Julião (PSB-PE) logo na primeira lista de depurações institucionais publicada pelos militares no dia 10 de abril de 1964, ressaltando ainda a Comissão da Verdade que "Francisco Juliao, fundador das Ligas Camponesas, foi preso e ficou na prisão até 1965, quando foi solto, beneficiado por um habeas corpus, exilando-se no México." (BRASIL, 2014, p. 14).

Vale mencionar que também se vincula à noção de reforma das instituições um caráter de responsabilização, seja institucional, seja pessoal, conhecida como depuração, purificação ou saneamento administrativo. A depuração constitui uma das medidas recorrentemente ligadas ao processo de reformas institucionais, constituindo a identificação e exoneração dos indivíduos que perpetraram violações a partir de seus cargos ou funções públicas. Nesse sentido, observam-se na história diferentes graus de intensidade na utilização desse mecanismo, talvez sendo a Alemanha Oriental a que tenha atingido maior representatividade, chegando ao número de cerca de 500 mil pessoas, 
ou seja, aproximadamente 3\% da população, removidas de suas funções públicas após o nazismo (BRITO, 2009, p. 64).

Nesse sentido, de maneira recorrente observa-se que as reformas institucionais estão associadas, na literatura, à necessidade de recuperar e conferir legitimidade e confiança às instituições públicas, após um período em que elas foram utilizadas como instrumento para a violação sistemática de direitos humanos (VAN ZYL, 2009, p. 87). De fato, como afirma Sousa Júnior (2012, p. 18), para além de reformar, é preciso reeducar e refuncionalizar as instituições, para evitar a repetição de ciclos de violência e estabelecer parâmetros democráticos e emancipatórios de políticas públicas.

No Brasil, Abrão e Torelly (2011, p. 224) identificam e sistematizam a realização de medidas de reformas institucionais ao longo dos 25 anos do processo de democratização, voltadas para o controle das Forças Armadas e reforma da segurança pública, como a extinção do Serviço Nacional de Informações (SNI); para transformações no sistema de justiça, como as novas atribuições conferidas ao Ministério Público e a criação dos tribunais eleitorais independentes, com autonomia financeira e administrativa; para variadas e amplas reformas no arcabouço legislativo do regime ditatorial, como as leis que criam as comissões de reparação; e para a criação de políticas de direitos humanos, como a criação da Secretaria de Direitos Humanos da Presidência da República e de programas de educação em direitos humanos no âmbito do Ministério da Educação. De maneira politicamente mais intensa, a estas reformas institucionais vieram somar-se os trabalhos da Comissão Nacional da Verdade (CNV), instalada no mês de maio de 2012.

Por fim, há que se ressaltar que em matéria de reformas institucionais o poder judiciário e o sistema de segurança apresentam-se na ponta das instituições públicas que devem figurar como objeto de reformas democratizantes, como avalia Silva Filho (2011, p. 282, grifo do autor):

O fortalecimento das instituições democráticas traz a imperiosidade da reforma das instituições públicas que, durante o regime de exceção, permitiram e se amoldaram à prática sistemática de crimes contra a humanidade, especialmente as instituições relacionadas à Justiça e à Segurança.

Considerando-se essa compreensão, serão analisados a seguir alguns elementos que envolvem a temática das reformas institucionais no que diz respeito ao poder judiciário e à segurança pública na experiência transicional brasileira.

\section{Algumas considerações sobre a inserção do poder judiciário na justiça de transição}

No que diz respeito ao poder judiciário brasileiro, a questão da necessidade das reformas institucionais como mecanismo de transição se apresenta à análise a partir de três elementos: a intensidade da legalidade autoritária para a justiça, a questão da cultura jurídica, e as consequências do fenômeno da expansão do protagonismo político da justiça. 
Tratando da dimensão e força estratégica da legalidade autoritária, verifica-se uma especial tendência no sentido da sua utilização para formatação das instituições públicas nos moldes do regime ditatorial. Em outras palavras, verifica-se um intenso manejo político e autoritário de reformas institucionais realizadas pela via legal, voltadas, de um lado, à produção de um revestimento e discurso de legalidade e consequente legitimidade à ditadura brasileira, ao passo em que se procedia, e, por outro lado, à reorganização do Estado para o uso da violência política e sistemática como forma de governo. Na centralidade dessa característica essencial da ditadura brasileira encontram-se os Atos Institucionais.

Como modelo mais gravoso e evidente, nesse sentido, deve ser analisado o Ato Institucional n. 5, de 13 de dezembro de 1968, ${ }^{8}$ que viria subjugar e afastar da apreciação judicial os atos políticos do governo militar (art. 11) e, de maneira bastante emblemática para a justiça, suspender o habeas corpus contra crimes políticos, contra a segurança nacional e a ordem econômica (art. 10), além de, como mecanismo de depuração institucional, suspender as garantias de vitaliceidade e inamovibilidade (art. $6^{\circ}$ ). Produzia-se, assim, um discurso e um efeito de legitimidade do regime autoritário, na medida em que se mantinha o aparente funcionamento de uma justiça politicamente neutralizada.

Como aponta o relatório final da CNV (2014, p. 19), em decorrência deste famigerado Ato Institucional "o Judiciario não tardou a ser atingido. Em janeiro de 1969, três ministros do Supremo Tribunal Federal, Victor Nunes Leal, Hermes Lima e Evandro Lins e Silva, foram aposentados compulsoriamente", o que acabou por provocar a demissão voluntária de outros dois ministros da Corte.

Além das variadas depurações no âmbito das instituições de justiça, observa-se que o AI-5 buscou produzir um efeito de afastamento da jurisdição em relação a questões revestidas de intensidade política, entre as quais se situavam, por evidência, aquelas voltadas à reivindicação e luta por direitos humanos. Desse modo, tal isolamento jurisdicional viria a aprofundar o distanciamento e aversão da cultura jurídica, no ambiente institucional de justiça, em relação às lutas sociais e violações de direitos, produzindo uma cultura judicial ora alienada, ora coagida, e ora condescendente com o regime autoritário, o que se reflete de maneira preocupante na prestação da justiça na atualidade.

Não há que se olvidar, ainda, que as regras de organização e disciplina vigentes ainda hoje no poder judiciário emanam da Lei Orgânica da Magistratura Nacional (Loman) (Lei Complementar n. 35, de 14 de março de 1979) (BRASIL, 1979), promulgada em pleno regime autoritário e cuja estrutura interna de verticalização do poder responde a uma concepção de controle da justiça pelo

\footnotetext{
8 "Ato Institucional n. 5, de 13 de dezembro de 1968:

Art. $6^{\circ}$ - Ficam suspensas as garantias constitucionais ou legais de: vitaliciedade, inamovibilidade e estabilidade, bem como a de exercício em funções por prazo certo;

$[\ldots]$

Art. 10 - Fica suspensa a garantia de habeas corpus, nos casos de crimes políticos, contra a segurança nacional, a ordem econômica e social e a economia popular;

Art. 11 - Excluem-se de qualquer apreciação judicial todos os atos praticados de acordo com este Ato institucional e seus Atos Complementares, bem como os respectivos efeitos." (BRASIL, 1968).
} 
executivo militarizado, em uma lógica na qual as cúpulas dos tribunais funcionam como mediação entre tal controle político e toda a complexa estrutura de justiça do País (ZAFFARONNI, 1995), com seus reflexos diretos sobre a cultura judicial.

De fato, conforme Boaventura de Sousa Santos (2009, p. 116), a cultura jurídica está inserida, de maneira indissociável, no âmbito da cultura política de uma sociedade, devendo ser compreendida como "o conjunto de orientações sobre valores e interesses que configuram um padrão de atitudes frente ao direito e aos direitos, e frente às instituições do Estado que produzem, aplicam, garantem ou violam o direito e os direitos."

Dessa forma, a questão da cultura jurídica dos agentes do sistema de justiça e a sua reprodução no tempo como uma cultura institucional atrelada, subjugada, mas também em parte aderida à ideologia imprimida no âmbito da legalidade autoritária (PEREIRA, 2010, p. 36), dizem muito a respeito da dificuldade do sistema de justiça em dialogar e lidar hoje com demandas que envolvam conflitos em direitos humanos, uma vez que poucas foram as medidas voltadas a uma profunda transformação na cultura jurídica e institucional no âmbito das suas instituições.

Como afirmado recentemente em trabalho conjunto com Sousa Júnior (2016, p. 156), nesse sentido, observa-se que "forjado sob uma cultura jurídica arcaica, atolada no discurso da neutralidade e cega pela luz do formalismo positivista", com o advento do regime democrático, o judiciário brasileiro entrou em curto-circuito, na expressão de Sousa Santos (2009), "ao se deparar com a nova tarefa de solucionar conflitos públicos e de interesse social, muitos dos quais referidos à violação ou efetivação dos direitos humanos, e carregados de alta intensidade política."

Observa-se, assim, um cenário de transição controlada e inacabada no âmbito da justiça, o que, para Gomes da Silva (1989, p. 28), poderia ser atribuído à condição "delegada" da Constituinte e a sua consequente configuração conservadora. Como lembram Bonavides e Andrade (1991, p. 451), nesse sentido, a configuração conservadora da Constituinte decorre mesmo do fato de que "foi ela a primeira Constituinte brasileira que não se originou da ruptura anterior das instituições."

Desse modo, sem ignorar a forte presença de forças conservadoras nos processos constituintes recentes, Gargarella (2011) apresenta uma interessante crítica à atuação das forças progressistas da América Latina, ao constatar que de um modo recorrente a sua estratégia de intervenção nas constituintes de transição dos regimes autoritários foi orientada para a conquista e expansão do rol de garantias e direitos fundamentais - o que notadamente possui um significado da maior importância para sociedades que buscavam a superação da violência política como forma de governo -, mas pouco se debruçou sobre a organização do poder e das respectivas instituições que fariam a mediação de execução, regulamentação, defesa e efetivação daqueles novos direitos trazidos para a essência do regime político e constitucional. Como afirma o constitucionalista argentino, "en la actualidad nos encontramos con fuerzas de izquierda que, desde las Convenciones Constituyentes en que participaron, trabajaron sobre la sección de los 'derechos' desentendiéndose de las reformas que se introducían, 0 no, en materia de 'organización del poder'." (GARGARELLA, 2011, p. 100, grifo do autor). 
Desse modo, o Brasil viu-se diante daquele curto-circuito histórico (SANTOS, 2009, p. 104), no que diz respeito à passagem direta e imediata da legalidade autoritária para um sistema constitucional de ampla garantia de novos direitos humanos, percorrendo subitamente um percurso legislativo de reconhecimento de direitos que levou séculos para se catalisar por meio de intensas lutas sociais e se consolidar em reflexos político-institucionais na história. De outro lado, o País depara-se, ainda, com uma estrutura política de justiça caracterizada pela ausência de rupturas e reformas institucionais voltadas à superação de uma cultura jurídica de cunho técnico-formalista, consolidada e potencializada pelo ambiente autoritário (SOUZA SANTOS, 2009, p. 107; SILVA FILHO, 2011, p. 282, 289).

Como resultado, a conquista da ampliação de direitos não foi acompanhada pela transformação da cultura institucional do poder judiciário que viria a aplicá-los, o que se comunicou e acabou por se traduzir, em sentido contrário, na forma de uma baixa capacidade institucional, em sentido técnico e operacional, da justiça brasileira para lidar de forma adequada com as novas demandas de direitos humanos, gerando um efeito de bloqueio institucional da justiça em relação aos direitos humanos no Brasil (MARÉS et al., 2014, p. 87). ${ }^{9}$

Em outro plano, fator de especial relevância no que diz respeito às transformações institucionais voltadas a uma cultura democrática no interior do poder judiciário é a questão da sua inserção, hoje, no cenário e fenômeno de expansão do protagonismo judicial, comumente conhecido pela sua dimensão mais polêmica, a denominada judicialização da política.

Nesses termos, parece necessário compreender dois elementos: de um lado, que essa expansão não constitui fenômeno isolado da arena política, específico do Brasil ou intencional por parte dos agentes do sistema de justiça. Por outro, que tal fenômeno se insere em uma tendência mais ampla, observada em todo o ocidente, variando na medida das diferentes estruturas políticas e econômicas dos Estados, com especial ascensão, na América Latina, nos regimes democráticos pós-ditaduras militares (VERONESE, 2009).

Isso importa, na medida em que esse processo de expansão judicial carrega consigo o desenvolvimento e a ampliação do contato entre o sistema de justiça e a sociedade, o que resulta em problemas quanto à efetivação dos direitos humanos em países onde as instituições judiciais não passaram por processos históricos de transformações políticas aptas a produzir a reconfiguração da cultura jurídica, nem por reformas institucionais inseridas no debate sobre a justiça de transição, como é o caso do Brasil.

Nesse sentido, a ausência de reformas institucionais orientadas pelos direitos humanos, no ambiente de transição, configura um quadro em que se amplia a interferência das instituições de justiça em temas políticos, sem que estas tenham sido capacitadas e seus agentes (trans)formados

\footnotetext{
9 Cf., nesse sentido, levantamento realizado pela Procuradoria Federal do Incra em pareceria com a Terra de Direitos em 2011, apontando a existência de cerca de 200 ações judiciais de desapropriação por interesse social, para fins de reforma agrária, e 250 ações judiciais de retomada de terras públicas paralisadas na justiça federal no ano 2009 (INSTITUTO DE COLONIZAÇÃO E REFORMA AGRÁRIA, 2009).
} 
em sua cultura jurídica, a fim de absorver demandas que não mais se referem somente ao direito penal como forma de controle social stricto sensu e à solução de problemas patrimoniais e contratuais entre indivíduos, uma vez que agora dizem respeito a litígios sobre casos estruturais de direitos humanos, envolvendo direitos fundamentais de sujeitos coletivos de direitos, aliados à realização de políticas públicas inseridas no bojo do Estado democrático.

Diante desses fatores, portanto, pode-se dizer que o poder judiciário brasileiro se apresenta como exemplo de um processo de transição controlada (ABRÃO; TORELLY, 2011, p. 232), ausente de rupturas e marcado pelo paradigma político e institucional do esquecimento e da negação de justiça, algo que caracteriza a transição brasileira. De fato, Silva Filho (2011, p. 289) aponta uma postura de envolvimento institucional e cultural dos agentes do poder judiciário brasileiro com o regime militar, em contraponto à ausência de rupturas, depuração e reforma institucional adequada, permitindo que ali se mantivesse viva uma mentalidade elitista e autoritária (ABRÃO; TORELLY, 2011, p. 236).

De fato, as consequências mais visíveis desse processo político de transição controlada no âmbito do poder judiciário se revelam, hoje, no descompromisso institucional em relação à efetivação e às violações de direitos humanos e na impunidade que se reproduz como cultura institucional, estimuladas, por seu turno, pela decisão do STF em relação à ADPF 153, que acabou por declarar a constitucionalidade da Lei de Anistia (SILVA FILHO, 2011, p. 299). Por essas condições em que se encontra o cenário institucional e transicional da justiça brasileira, Abrão e Torelly (2011, p. 230) vêm concluir que "a mais notória dimensão de não desenvolvimento da justiça transicional brasileira é, sem dúvida, a dimensão da justiça."

\section{Os sistemas de segurança pública e a justiça de transição}

O sistema político e as agências de segurança pública no período da ditadura civil-militar no Brasil foram orientados pela doutrina de segurança nacional, ${ }^{10}$ da qual decorre uma concepção do opositor político como inimigo ${ }^{11}$ do Estado, sujeito tacitamente às leis de guerra e eliminação.

\footnotetext{
10 Cf. Huggins (1998). Temos também, como exemplo, o fato de que "a partir de 1964 as Polícias Militares passaram a ser comandadas por Oficiais do Exército, que repassaram às Corporações os valores adquiridos naquela Força Armada. Com isso as Polícias Militares passaram a dar maior prioridade à defesa interna e à segurança nacional, em detrimento da segurança pública. Começava uma era em que a Polícia Militar seria considerada o braço visível do período ditatorial." (MARCINEIRO; PACHECO, 2005). Para um aprofundamento na doutrina de segurança nacional e a perspectiva de guerra a ela inerente cf. Comblin (1978).

11 De acordo com Zaffaroni (2007, p. 18): "A essência do tratamento diferenciado que se atribui ao inimigo consiste em que o direito lhe nega sua condição de pessoa. Ele só é considerado sob o aspecto de ente perigoso ou daninho. Por mais que a idéia seja matizada, quando se propõe estabelecer a distinção entre cidadãos (pessoas) e inimigos (não-pessoas), faz-se referência a seres humanos que são privados de certos direitos individuais, motivo pelo qual deixaram de ser considerados pessoas, e esta é a primeira incompatibilidade que a aceitação dos hostis, no direito, apresenta com relação ao principio do Estado de Direito." É válido dizer que o "direito penal do inimigo" sustentado por Zafaroni não se restringe apenas ao período ditatorial, mas está em plena expansão no cenário contemporâneo, em sintonia com o populismo penal, uma vez que o "inimigo" não é mais o subversivo que se opõe ao governo constituído, mas pode ser os excluídos, os estrangeiros, os movimentos sociais, os camponeses, etc.
} 
Nesse cenário, tivemos um recrudescimento da perseguição aos opositores políticos do regime que se opuseram à ditadura, sendo utilizadas as práticas de execução sumária e desaparecimento forçado, assim como o sequestro, o banimento e a tortura, entre outras violações de direitos humanos, típicas de um terrorismo de Estado. Essa doutrina do inimigo interno (VALDES, 1980) desencadeou nas agências estatais de segurança brasileiras, e em diversos países da América Latina, submetidos a Estados de exceção e a períodos de ditadura civil-militar, uma lógica de guerra ao crime, ${ }^{12}$ na qual os opositores políticos dos governos foram criminalizados e perseguidos como inimigos do poder constituído.

A estrutura da repressão foi organizada para obter informações e conter, por todos os meios, os opositores políticos. A conjugação de agências policiais civis e militares e os órgãos de segurança e informação das Forças Armadas criaram um subsistema DOPS/DOI - CODI, sendo as primeiras, estaduais, geralmente designadas por Departamento de Ordem Política e Social (DOPS), e as segundas, associando um órgão de inteligência (Destacamento de Operações de Informações - DOI) a um órgão operativo (Centro de Operações de Defesa Interna - CODI). Daí falarmos em subsistema DOPS/DOI - CODI. ${ }^{13}$

Em virtude dessa política de segurança nacional, tivemos a disseminação, no sistema de segurança pública, de prisões arbitrárias de suspeitos e prisões para averiguação, sem ordem judicial, denúncias de torturas como método de investigação e busca da verdade, existência de grupos de extermínio formados por policiais em diversas unidades da federação, entre outras graves violações de direitos humanos (ADORNO, 2008), que permaneceram, a despeito da instituição de uma nova ordem jurídica constitucional inaugurada com a Constituição Federal de 1988. ${ }^{14}$

Há, portanto, pontos de tensão entre o novo conceito de segurança pública trazido pela Carta Constitucional de 1988, que tenta introduzir no Estado mecanismos democráticos de acesso à justiça e garantia de direitos, mas que manteve, basicamente, o aparato de segurança com as mesmas estruturas e práticas institucionais difundidas no regime militar. É preciso, nesse sentido, superar

\footnotetext{
12 Conforme sintetiza Sozzo (2009, p. 33-65): "La guerra como metáfora abriga una percepción dicotómica y maniqueista, en la que existen dos bandos, la resolución de su enfrentamiento solo puede ser consecuencia de la neutralización o eliminación de uno de ellos."

13 "As agências policiais que promoviam a criminalização secundária dessa programação excediam sistemática e rotineiramente suas balizas. Conjugando repartições policiais civis e militares, o subsistema penal DOPS/DOI-CODI, especialmente entre 1968 e 1974 - quando organizações políticas clandestinas optaram pelo enfrentamento armado -, torturou, matou e ocultou o cadáver de centenas de pessoas. O subsistema penal DOPS/DOI-CODI engendrou uma estrutura que colocou em contato com a repressão manifestamente política policiais que, a partir do final dos anos cinqüenta, haviam dinamizado procedimentos ilegais de execução sumária de suspeitos ou acusados, geralmente de crimes patrimoniais, ou mesmo simplesmente de mendigos, sob a designação de 'esquadrão da morte'." (ZAFFARONI; BATISTA; SLOKAR, 2011, p. 478).

14 Conforme expressa em seu relatório nacional de direitos humanos, a rede Plataforma Dhesca (PLATAFORMA..., $2009, \mathrm{p}$. 41): “[...] destaca-se que a violação sistemática dos direitos humanos pelo Estado brasileiro, em especial da população pobre e negra, é justificada em nome da 'segurança pública', entendida a partir de uma concepção autoritária e repressiva. Nessa perspectiva, há uma supervalorização das medidas e ações de segurança marcadas pela força e uma vergonhosa desvalorização e descuido com a garantia dos direitos humanos e políticas sociais. [...] As comunidades populares que vivenciam uma situação crônica de violência armada, com acesso precário a serviços básicos de baixíssima qualidade, e as centenas de milhares de pessoas encarceradas em condições terrivelmente indignas, expõem de forma brutal e perversa os limites e contradições das políticas de segurança pública ainda hegemônicas e do modelo de desenvolvimento brasileiro, marcado pela exclusão de grandes contingentes e pela manutenção e acirramento de desigualdades diversas."
} 
o paradigma da segurança nacional que orientou os órgãos nacionais para combater inimigos da ditadura instaurada em 1964 (LIMA, 2011). De acordo com a redação do art. 144 da Constituição Federal, a segurança pública é um dever do Estado e também uma responsabilidade de todos (BRASIL, 1988). Portanto, nesse novo modelo, a permanência de práticas autoritárias e graves violações por parte dos agentes estatais de segurança é incompatível com o regime democrático e um Estado organizado para a proteção e promoção de direitos.

Democratizar o sistema de segurança pública no Brasil significa, então, estabelecer como prioridade e objetivo a proteção de direitos em detrimento de uma lógica de "guerra ao crime". Para tanto, é preciso construir mecanismos institucionais capazes de romper com a herança autoritária presente no modelo brasileiro de sistema penal e de segurança que ainda possui um caráter não apenas autoritário, como também militarizado e seletivo. ${ }^{15}$

Nesse sentido, ressalta-se o Programa Nacional de Direitos Humanos (PNDH 3), criado pelo Governo Federal com base no art. 84, inciso IV, da Constituição, pelo Decreto n. 1904, de 13 de maio de 1996, "contendo diagnóstico da situação desses direitos no País e medidas para a sua defesa e promoção, na forma do Anexo deste Decreto." (BRASIL, 1996). Apresentado pelo Poder Executivo em 2009, sua terceira versão, o PNDH 3, possui tópico específico sobre as reformas institucionais no sistema de segurança, com diversas diretrizes destinadas a promover alterações voltadas para a ruptura com os resquícios autoritários ditatoriais, e trata-se do "Eixo Orientador IV: Segurança Pública, Acesso à Justiça e Combate à Violência". ${ }^{16}$ A Diretriz 25 do PNDH 3 é voltada para a "Modernização da legislação relacionada com a promoção do direito à memória e à verdade, fortalecendo a democracia', a qual tem como Objetivo Estratégico I, "Suprimir do ordenamento jurídico brasileiro eventuais normas remanescentes de períodos de exceção que afrontem os compromissos internacionais e os preceitos constitucionais sobre Direitos Humanos." (BRASIL, 2009).

Para concretizar as ações de desenvolvimento do direito à memória e à verdade, no contexto da redemocratização nacional, é preciso reconhecer a extensão dos crimes da ditadura, e apurar as responsabilidades pelas graves violações de direitos humanos do período de exceção, de modo isento e republicano.

O risco de não empreendermos as reformas institucionais e as ações de justiça de transição no poder judiciário e no sistema de segurança pública reside em ameaça permanente à própria demo-

\footnotetext{
15 "Nuestra historia se encarga de demostrarnos sobradamente que los sistemas penales latinoamericanos no surgen en función de códigos - legislaciones, originarias o importadas, sino que desde los tiempos de la primera colonización se presentan como un ejercicio de poder controlador disciplinario 'militarizado' ejercido sobre las mayorías y sobre los disidentes." (ZAFFARONI, 1993, p. 68, grifo nosso).

16 Ao todo, esse Eixo Orientador possui sete Diretrizes e 29 objetivos estratégicos, além de várias recomendações aos estados e ao Distrito Federal. As diretrizes desse Eixo são: Diretriz 11: Democratização e modernização do sistema de segurança pública. Diretriz 12: Transparência e participação popular no sistema de segurança pública e justiça criminal. Diretriz 13: Prevenção da violência e da criminalidade e profissionalização da investigação de atos criminosos. Diretriz 14: Combate à violência institucional, com ênfase na erradicação da tortura e na redução da letalidade policial e carcerária. Diretriz 15: Garantia dos direitos das vítimas de crimes e de proteção das pessoas ameaçadas. Diretriz 16: Modernização da política de execução penal, priorizando a aplicação de penas e medidas alternativas à privação de liberdade e melhoria do sistema penitenciário. Diretriz 17: Promoção de sistema de justiça mais acessível, ágil e efetivo, para o conhecimento, a garantia e a defesa dos direitos (BRASIL, 2009, p. 129).
} 
cracia. A construção da memória e da verdade em sociedades que vivem períodos de exceção tem por escopo garantir a ruptura com valores autoritários. Nesse sentido:

Há indícios que, naqueles países onde se implementaram as políticas da justiça transicional - comissões da verdade, julgamentos penais, reparações, reformas institucionais e políticas de memórias -, os valores dos cidadãos em respeito ao método democrático e a oposição da volta do autoritarismo de coturno ao poder receberam impactos positivos dos mecanismos da justiça transicional. Por outro lado, no Brasil, o efeito indica ser o inverso: os brasileiros e as brasileiras permanecem reconhecendo nas Forças Armadas um poder moderador e político, em desprezo às instituições democráticas como forma de resolução de conflitos e atendimento de demandas sociais. (LENTZ, 2012, p. 163).

Os trabalhos desenvolvidos pela Comissão Nacional da Verdade constituíram ações importantes para elucidar a extensão, as circunstâncias e os responsáveis pelos crimes cometidos durante a ditadura civil-militar. ${ }^{17} \mathrm{O}$ ponto que sintetiza a relação entre os objetivos da justiça de transição e as reformas no sistema de segurança reside na necessidade de empreender ações de depuração institucional em países que viveram períodos de exceção autoritária de ditadura civil-militar como o Brasil. Instituições que violam direitos humanos no período democrático foram gradualmente identificadas nos relatórios da Comissão Nacional da Verdade para que sejam reformadas ou extintas, como a polícia, os serviços de inteligência, o poder judiciário ou o exército. ${ }^{18}$

A consideração das recomendações sobre as reformas institucionais no sistema de segurança pública de outros atores contribui para o aumento da densidade política do debate sobre a justiça de transição no Brasil e aproveita o acúmulo que esses grupos possuem nos temas voltados à redução da violência estatal. Debates como a desmilitarização das polícias, a transparência nos serviços de inteligência policial e as questões relacionadas à letalidade e ao uso da força estão em permanente discussão na sociedade e são fundamentais no âmbito das recomendações para evitar a repetição das graves violações de direitos humanos.

Em relação à desmilitarização das polícias, por exemplo, as demandas por reformas institucionais no sistema de segurança pública não surgem apenas da sociedade civil. As iniciativas partem de parcela expressiva de policiais militares, sobretudo praças, de patentes inferiores na rígida estrutura de hierarquia e disciplina dessas corporações. Exemplo disso foi uma diretriz aprovada na $1^{\text {a }}$ Conferência Nacional de Segurança Pública ( $1^{\text {a }}$ Conseg), realizada pelo Ministério da Justiça, em 2009, que teve por objetivo debater com a sociedade brasileira, em processo inédito, os temas e propostas para a segurança. De acordo com essa diretriz, aprovada na $1^{\text {a }}$ Conseg, que teve apoio

\footnotetext{
17 De acordo com Hayner (2011, p. 23): "truth commissions are well positioned to evaluate the institutional responsibility for abuses, and to outline the reforms needed to prevent further abuses. These typically focus on the police, military, and judicial system, The recommendations in this area have sometimes been extensive and detailed, and often result in considerable implementation efforts by the donor community as well as the government. Successful implementation of truth commission recommendations, however, continues to be weak." 18 "Nesse sentido, é imperioso mudar radicalmente, e em alguns casos dissolver, as instituições responsáveis pelas violações dos direitos humanos [...] No geral, as comissões da verdade estão habilitadas para fazer sugestões em seus relatórios finais a respeito das medidas legais, administrativas e institucionais que devem ser tomadas para evitar o ressurgimento dos crimes sistemáticos do passado." (VAN ZYL, 2009, p. 37-42).
} 
expressivo dos praças da polícia militar, a desmilitarização da segurança pública deveria ocorrer nos seguintes termos:

Realizar a transição da segurança pública para atividade eminentemente civil; desmilitarizar as polícias; desvincular a polícia e corpos de bombeiros das forças armadas; rever regulamentos e procedimentos disciplinares; garantir livre associação sindical, direito de greve e filiação político-partidária; criar código de ética único, respeitando a hierarquia, a disciplina e os direitos humanos; submeter irregularidades dos profissionais militares à justiça comum.

Denota-se dessa diretriz aprovada que, para parte de profissionais de segurança pública, a estrutura militarizada limita direitos dos próprios agentes estatais. Nesse sentido, a desmilitarização das polícias militares estaduais também consta entre as conclusões e recomendações que compõem o Relatório Final, da Comissão Nacional da Verdade (CNV), em 2014:

A atribuição de caráter militar as polícias militares estaduais, bem como sua vinculação às Forças Armadas, emanou de legislação da ditadura militar, que restou inalterada na estruturação da atividade de segurança pública fixada na Constituição brasileira de 1988. Essa anomalia vem perdurando, fazendo com que não só não haja a unificação das forças de segurança estaduais, mas que parte delas ainda funcione a partir desses atributos militares, incompatíveis com o exercício da segurança pública no Estado democrático de direito, cujo foco deve ser o atendimento ao cidadão. Torna-se necessário, portanto, promover as mudanças constitucionais e legais que assegurem a desvinculação das policias militares estaduais das Forças Armadas e que acarretem a plena desmilitarização desses corpos policiais, com a perspectiva de sua unificação em cada estado.

As reformas no sistema de segurança são, portanto, fundamentais para superar uma transição democrática incompleta para a democracia e não estão voltadas apenas para as violações de direitos humanos do passado autoritário, mas têm por intuito, sobretudo, reformar órgãos e eliminar práticas de exceção que, paradoxalmente, estão sendo utilizadas por agentes estatais de segurança no âmbito de um Estado democrático de direito.

\section{Considerações finais}

O processo de transição e de consolidação do direito à memória e à verdade no Brasil é tardio, sugerindo, ainda, a demanda por reformas e até mesmo extinção de instituições que não se adequaram à ordem constitucional instituída pela Constituição Federal de 1988. O cenário institucional de transição sugere a permanência de resquícios autoritários no poder judiciário e nas agências estatais de segurança e órgãos correlatos, convivendo com violações de direitos humanos e práticas autoritárias de exceção ainda utilizadas.

Sobre agências e membros do sistema de segurança pública pesam ainda acusações de tortura, execuções sumárias, seletividade no controle penal, entre outras violações de direitos humanos que não se concretizariam sem a cumplicidade do Poder Judiciário, inclusive o Ministério Público, na 
omissão com que, por vezes, exerce o controle externo da atividade policial. Como se observa, reformas institucionais nesses órgãos são fundamentais para a construção e consolidação da democracia, aprimorando práticas que necessitam ser submetidas a processos de maior transparência e controle social.

Assim, cumpre reconhecer o protagonismo da sociedade civil em articulação com o poder executivo, na construção do direito à memória e à verdade na democracia brasileira, sobretudo órgãos estratégicos para o tema da transição, como a Comissão Nacional da Verdade, com as demais comissões da verdade espalhadas nos diversos segmentos e estados do País, além da Comissão de Anistia do Ministério da Justiça e a Comissão Especial de Mortos e Desaparecidos Políticos da Secretaria de Direitos Humanos da Presidência da República. No mesmo sentido, o poder judiciário e o poder legislativo também devem contribuir com o processo de efetiva transição democrática no Brasil e demandam estudo específico sobre a memória e a verdade institucional.

Além das reparações administrativas e judiciais oferecidas às vítimas das graves violações de direitos humanos, verifica-se que as reformas institucionais orientadas para a extirpação de resquícios autoritários do período de exceção consistem em importantes objetivos da justiça de transição. Passados mais de 50 anos do golpe militar, ainda se observa a necessidade histórica de identificação de estruturas institucionais incompatíveis com os direitos humanos e os valores democráticos que a sociedade brasileira almeja consolidar.

\section{Referências}

ABRÃO, Paulo; TORELLY, Marcelo D. As dimensões da justiça de transição no Brasil, a eficácia da Lei de Anistia e as alternativas para a verdade e justiça. In: PAYNE, Leigh; ABRAO, Paulo; TORELLY, Marcelo D. (Org.). A anistia na era da responsabilização: o Brasil em perspectiva internacional e comparada. Brasília: Ministério da Justiça, Comissão da Anistia; Oxford: Oxford University, Latin American Centre, 2011.

ADORNO, Sérgio. Políticas Públicas e Justiça Penal. Cadernos Adenauer IX, n. 4. Segurança Pública. Rio de Janeiro: Fundação Konrad Adenauer, 2008.

BONAVIDES, Paulo; ANDRADE, Paes de. História constitucional do Brasil. 3. ed. Rio de Janeiro, 1991.

BRASIL. Ato Institucional n 5 , de 13 de dezembro de 1968. São mantidas a Constituição de 24 de janeiro de 1967 e as Constituições Estaduais; O Presidente da República poderá decretar a intervenção nos estados e municípios, sem as limitações previstas na Constituição, suspender os direitos políticos de quaisquer cidadãos pelo prazo de 10 anos e cassar mandatos eletivos federais, estaduais e municipais, e dá outras providências. Diário Oficial da União, Brasília, DF, 13 dez. 1968. Disponível em: <http://www.planalto.gov.br/ccivil_03/AIT/ait-05-68.htm>. Acesso em: 07 jul. 2013.

BRASIL. Constituição. República Federativa do Brasil. Brasília, DF: Senado Federal, 05 out. 1988. Disponível em: <http://www.planalto.gov.br/ccivil_03/Constituicao/Constituicao.htm>. Acesso em: 07 jul. 2013. 
BRASIL. Decreto n. 1904, de 13 de maio de 1996. Institui o Programa Nacional de Direitos Humanos - PNDH. Diário Oficial da União, Brasília, DF, 13 maio 1996. Disponível em: <http://www. planalto.gov.br/ccivil_03/decreto/d1904.htm>. Acesso em: 15 jul. 2013.

BRASIL. Decreto n. 7.037, de 21 de dezembro de 2009. Aprova o Programa Nacional de Direitos Humanos - PNDH-3 e dá outras providências. Secretaria Especial dos Direitos Humanos da Presidência da República, Brasília, DF, 2010.

BRASIL. Lei Complementar n. 35, de 14 de março de 1979. Dispõe sobre a Lei Orgânica da Magistratura Nacional. Diário Oficial da União, Brasília, DF, 15 mar. 1979. Disponível em: <http://www. planalto.gov.br/ccivil_03/leis/lcp/lcp35.htm>. Acesso em: 01 nov. 2014.

BRASIL. Presidência da República. Comissão nacional da verdade. Balanço de atividades: 1 ano de Comissão Nacional da Verdade. Brasília, DF: Imprensa Oficial, 2013.

BRITO, Alexandra B. Justiça transicional e a política da memória: uma visão global. Revista Anistia Política e Justiça de transição, Brasília, DF: Ministério da Justiça, n. 1, p. 56-83, jan./jun. 2009.

COMBLIN, Joseph. A ideologia de segurança nacional: o poder militar na América Latina. Rio de Janeiro: Civilização Brasileira, 1978.

DOMINGUES DA SILVA, Angela Moreira. Ditadura e Justiça Militar no Brasil: A atuação do Superior Tribunal Militar (1964-1980). 2001. Tese (Doutorado em História)-Fundação Getúlio Vargas, Rio de Janeiro, 2011.

GARGARELLA, Roberto. Pensando sobre la reforma constitucional en América Latina. In: GARAVITO, César Rodríguez (Coord.). El derecho en América Latina: un mapa para el pensamiento jurídico del siglo XXI. Colección Derecho y Política. Buenos Aires: Siglo Veintiuno Editores, 2011. p. 87-108.

HAYNER, Priscilla B. Unspeakable truths. Transitional Justice and the Challenge of Truth Commissions. 2. ed. London: Routledge, 2011.

HUGGINS, Martha K. Polícia e política. São Paulo: Cortez, 1998.

INSTITUTO DE COLONIZAÇÃO E REFORMA AGRÁRIA. Relatório do INCRA aponta mais de 200 processos de desapropriação parados no Judiciário. 27 abr. 2009. Disponível em: <http://www. incra.gov.br/index.php/noticias-sala-de-imprensa/noticias/8825-relatorio-do-incra-aponta-mais-de-200-processos-de-desapropriacao-parados-no-judiciario>. Acesso em: 25 jan. 2013.

LENTZ, Rodrigo. A justiça transicional entre o institucionalismo dos direitos humanos e a cultura política: uma comparação do Brasil com o Chile e a Argentina (1995-2006). In: SILVA FILHO, José Carlos Moreira da (Org.). Justiça de Transição no Brasil. Violência, justiça e segurança. Porto Alegre: EDIPUCRS, 2012. p. 149-170.

LIMA, Renato Sérgio de. Segurança pública e os 20 anos da Constituição Cidadã: entre palavras e números. São Paulo: Alameda, 2011.

MARCINEIRO, Nazareno; PACHECO, Giovanni C. Polícia comunitária: evoluindo para a polícia do século XXI. Florianópolis: Insular, 2005. 
MARÉS, Carlos, SAUER, Sergio, ESCRIVÃO FILHO, Antonio, FRIGO, Darci, PRIOSTE, Fernando (Coord.). Casos emblemáticos experiências modelo de mediação: análise para uma cultura institucional de soluções alternativas de conflitos fundiários rurais. Brasília, DF: Ministério da Justiça, Secretaria da Reforma do Judiciário, 2013.

MARTINS, José de Sousa. Expropriação e violência: a questão política no campo. São Paulo: Hucitec, 1980.

PEREIRA, Anthony. Ditadura e repressão: o autoritarismo e o estado de direito no Brasil, no Chile e na Argentina. São Paulo: Paz e Terra, 2010.

PLATAFORMA BRASILEIRA DE DIREITOS ECONÔMICOS, SOCIAIS, CULTURAIS E AMBIENTAIS. Desafios dos direitos humanos no Brasil e a experiência das relatorias nacionais em Dhesca. Informe 2007-2009. Curitiba, 2009. Disponível em: <www.dhescabrasil.org.br>. Acesso em: 20 jun. 2013.

QUINALHA, Renan Honório. Justiça de transição: contornos do conceito. São Paulo: Outras Expressões; Dobra editorial, 2013.

SAUER, Sérgio. Terra e modernidade: a reinvenção do campo brasileiro. São Paulo: Expressão Popular, 2010.

SILVA FILHO, José Carlos Moreira. Memória e reconciliação nacional: o impasse da anistia na inacabada transição democrática brasileira. In: PAYNE, Leigh; ABRÃO, Paulo, TORELLY, Marcelo (Org.). A anistia na era da responsabilização: o Brasil em perspectiva internacional e comparada. Brasília, DF: Comissão de Anistia; Oxford: Oxford University, Latin American Centre, 2011.

SILVA, José Gomes da. Buraco negro: a reforma agrária na constituinte de 1987-1988. Rio de Janeiro: Paz e Terra, 1989.

SOUSA JÚNIOR, José G. (Org.). Da universidade necessária à universidade emancipatória. Brasília: Ed. Unb, 2012.

SOUSA SANTOS, Boaventura de. Sociología jurídica crítica: para un nuevo sentido común en el derecho. Madrid: Bogotá: Trotta; Ilsa, 2009.

SOZZO, M. Populismo punitivo, proyecto normalizador y "prisión-depósito" en Argentina. Revista Sistema Penal \& Violencia. Porto Alegre: PUCRS, n. 1, p. 33-65, 2009.

TEITEL, Ruti. Transitional justice genealogy. Harvard human rights journal, v. 16, p. 69-94, 2003.

VALDES, Jorge T. El terrorismo de Estado: la doctrina de seguridad nacional en el Cono Sur. Revista Nueva Sociedad, México: Nueva Imagem, 1980.

VAN ZYL, Paul. Promovendo a justiça transicional em sociedades pós-conflito. Revista Anistia Politica e Justiça de transição, Brasília, DF: Ministério da Justiça, n. 1, p. 32-55, jan./jun. 2009.

ZAFFARONI, Eugenio Raul; BATISTA, Nilo; ALAGIA, Alejandro; SLOKAR, Alejandro. Direito penal brasileiro. Teoria geral do direito penal. Rio de Janeiro: Revan, 2011. v. 1. 
ZAFFARONI, Eugenio Raul. Derechos humanos y sistemas penales en América Latina. In: HULSMAN, Louk. Criminología crítica y control social I: el poder punitivo del Estado. Buenos Aires: Juris, 1993.

ZAFFARONI, Eugenio Raul. Poder Judiciário: crises e desacertos. São Paulo: Revista dos Tribunais, 1995.

ZAFFARONI, Eugenio Raul. O inimigo no direito penal. Rio de Janeiro: Revan, 2007.

Data da submissão: 30 de novembro de 2014 Avaliado em: 13 de junho de 2016 (AVALIADOR A) Avaliado em: 15 de abril de 2017 (AVALIADOR B) Aceito em: 27 de julho de 2017 